\title{
A EROSIVIDADE DAS CHUVAS NA ÁREA DE INFLUÊNCIA DA UHE AMADOR AGUIAR I, BACIA DO RIO ARAGUARI - MG
}

\author{
Juliana Sousa Pereira \\ Instituto de Geografia - Universidade Federal de Uberlândia \\ julianasousa.geo@hotmail.com \\ Silvio Carlos Rodrigues \\ Instituto de Geografia - Universidade Federal de Uberlândia \\ silgel@ufu.br
}

\begin{abstract}
RESUMO
A erosão hídrica dos solos se configura como um dos grandes problemas em áreas destinadas as atividades agropecuárias. Os impactos gerados pelo desencadeamento dos processos erosivos podem reduzir a produtividade agrícola, ocasionar o assoreamento dos reservatórios para geração de energia elétrica e desvalorizar as propriedades rurais, acarretando prejuízos ambientais, sociais e econômicos. A erosividade é definida como a capacidade das chuvas em causar erosão pela desagregação e transporte das partículas do solo, se constituindo um dos componentes importantes na determinação da perda de solo por erosão laminar. Este estudo teve como objetivo estimar e mapear a erosividade mensal e anual na área de influência da UHE Amador Aguiar I. Nesta perspectiva, utilizaram-se dados de precipitação de seis estações pluviométricas, referentes ao período de 1981 a 2011. Os cálculos da erosividade foram realizados com base na equação proposta por Nascimento (1998). Os índices de erosividade anual variaram de 8183,8 MJ.mm/ha- ${ }^{1} \cdot h^{-1}$ a $9948 \mathrm{MJ} . \mathrm{mm} / \mathrm{ha}^{-1} \cdot \mathrm{h}^{-1}$. Para a espacialização dos valores foi empregado 0 método de interpolação Krigagem ordinária.
\end{abstract}

Palavras-chave: Erosão hídrica. Conservação dos solos. Precipitação pluviométrica.

\section{TITLE THE EROSIVITY OF RAINS IN THE AREA OF INFLUENCE OF UHE AMADOR AGUIAR I, ARAGUARI RIVER BASIN - MG}

\begin{abstract}
Water erosion of soils is configured as a major problem in areas for farming activities. The impacts generated by triggering erosion can reduce the agriculture productivities, causing siltation of reservoirs for power generation and depreciate rural properties, provoking environmental, social and economic losses. The erosivity is defined as the ability of the rainfall erosion by the breakdown and transport of soil particles, becoming an important component in determining the soil loss by sheet erosion. This study aimed to estimate and map the monthly and annual erosivity in the area of influence of UHE Amador Aguiar I. In this perspective, we used rainfall data from 10 rainfall stations, for the period 1981-2011. The calculations were performed erosivity based on the equation proposed by Nascimento (1998). The annual erosivity indices ranged from $8183,8 \mathrm{MJ} \cdot \mathrm{mm} / \mathrm{ha}^{-1} \cdot \mathrm{h}^{-1}$ a $9948 \mathrm{MJ} . \mathrm{mm} / \mathrm{ha}-$ ${ }^{1} \cdot h^{-1}$. For spatial distribution of the values we used the interpolation method, Ordinary Kriging.
\end{abstract}

Keywords: Water erosion. Soil conservation. Rainfall.

\section{INTRODUÇÃO}

A erosão do solo tem se constituído um assunto relevante no Brasil e em vários outros países, em virtude dos expressivos prejuízos de ordem física, financeira e social (OLIVEIRA et al., 2010). A preocupação em compreender a dinâmica dos processos erosivos e os impactos gerados, assim como, o desenvolvimento de metodologias de investigação e até mesmo a elaboração de técnicas de mitigação, faz com que essa temática esteja em constante vigência.

\begin{tabular}{llllll}
\hline Caminhos de Geografia & Uberlândia - MG & v. 19, n. 68 & Dez/2018 & p. 186-199 & Página 186
\end{tabular}


Diversos autores destacam que a cada ano em todo território brasileiro são perdidos milhões de toneladas de solo agrícola, devido à erosão laminar. As perdas anuais de solo em áreas ocupadas por lavouras e pastagens ultrapassam 500 milhões de toneladas, acarretando custos adicionais para as propriedades rurais e também prejuízos econômicos e ambientais para o país (LEPSCH, 2010; BERTONI e LOMBARDI NETO, 2012).

Os valores relacionados às perdas de solo podem ser estimados com o emprego de modelos preditivos de erosão, nos quais, a Equação Universal de Perdas de Solos (USLE), proposta por Wischmeier e Smith (1978) assume grande importância, configurando-se como um dos modelos mais utilizados. A USLE é composta por vários fatores que exercem influência nos processos erosivos. Porém, para esse trabalho será considerado a erosividade das chuvas, denominada de fator $\mathrm{R}$.

Trabalhos sobre a variabilidade espacial e a distribuição da erosividade da chuva têm sido realizados em algumas regiões do Brasil, com o propósito de identificar os períodos mais críticos em virtude da precipitação elevada, e neste âmbito, propor medidas para reduzir a força cisalhante das gotas de chuva e do escoamento superficial, visando prevenir, além do empobrecimento dos solos, também o assoreamento dos cursos hídricos.

O escoamento superficial transporta as partículas em suspensão, nutrientes, matéria orgânica, sementes e defensivos agrícolas, causando danos à produção e a poluição das nascentes. Nesse sentido, as perdas de solos por erosão hídrica podem elevar os custos, à medida que se torna necessário o maior emprego de fertilizantes e corretivos (PRUSKI, 2009).

Pesquisas relacionadas à qualidade de água e a produção de sedimentos em alguns córregos pertencentes à área de estudo têm demonstrado a existência de feições erosivas e as suas relações com as atividades antrópicas (PEREIRA, J.S. 2014). Oliveira (2006) indica a ocorrência de sulcos e ravinas ao longo da bacia hidrográfica do córrego Pindaíba e consequentemente o assoreamento das margens do córrego, sobretudo próximo à sua foz.

Chuquipiondo (2007), através de seções batimétricas estimou que as taxas de assoreamento da calha do rio Araguari, na área do Trecho de Vazão Reduzida (TVR) são de aproximadamente $0,5 \mathrm{~cm}$ por ano. Os sedimentos oriundos da erosão laminar, podem se acumular nas baixas vertentes e também nos cursos d'água (RITTER e ENG, 2012). O depósito de sedimentos acarreta o assoreamento das nascentes dos rios, reduz a disponibilidade hídrica e diminui a vida útil dos reservatórios.

A determinação dos valores da erosividade das chuvas, ao longo do ano, permite a identificação dos meses em que os riscos de perdas de solo são mais acentuados. Assim, é possível a adoção de práticas de manejo capazes de diminuir o impacto das gotas de chuva no solo (WISCHMEIER e SMITH, 1978; BERTONI e LOMBARDI NETO, 2012).

Neste contexto, os estudos sobre a erosividade das chuvas em bacias de drenagens são de grande valia para os órgãos gestores de bacias hidrográficas e para comunidade em geral. Uma vez que, possibilitando o maior entendimento da distribuição da precipitação ao longo dos anos, permite também a adoção de medidas necessárias para aumentar a superfície de infiltração evitando assim, o desencadeamento da erosão acelerada dos solos. O objetivo do presente trabalho é de calcular e espacializar os valores da erosividade anual na área de influência da UHE Amador Aguiar I, com o intuito de obter a variabilidade espacial desse fator, considerando a série histórica de 30 anos.

\section{Localização da área de estudo}

A área de estudo desta pesquisa é a área de influência da UHE Amador Aguiar I (UHE-AAI) que está situada entre as coordenadas geográficas: $18^{\circ} 42^{\prime} 0^{\prime \prime}-18^{\circ} 58^{\prime} 0^{\prime \prime}$ de latitude sul e $47^{\circ} 56^{\prime} 0^{\prime \prime}-48^{\circ} 15^{\prime}$ 30 " de longitude, a oeste do meridiano de Greenwich, possuindo $461,60 \mathrm{~km}^{2}$ de área total (Figura 1). A UHE - AAl está inserida na Bacia do Rio Araguari, localizada na porção oeste do Estado de Minas Gerais, abrangendo as regiões do Triângulo Mineiro e Alto Paranaíba. A UHE-AAI foi construída no rio Araguari, afluente da margem esquerda do rio Paranaíba, na porção de seu médio/baixo curso, entre o remanso do UHE Amador Aguiar II e a jusante da UHE Miranda, compreendendo áreas dos municípios mineiros de Uberlândia, Araguari e Indianópolis.

$\begin{array}{llllll}\text { Caminhos de Geografia } & \text { Uberlândia - MG } & \text { v. 19, n. } 68 & \text { Dez/2018 } & \text { p. 186-199 } & \text { Página } 187\end{array}$


Figura 1: Mapa de localização da Área de Influência da UHE Amador Aguiar I.

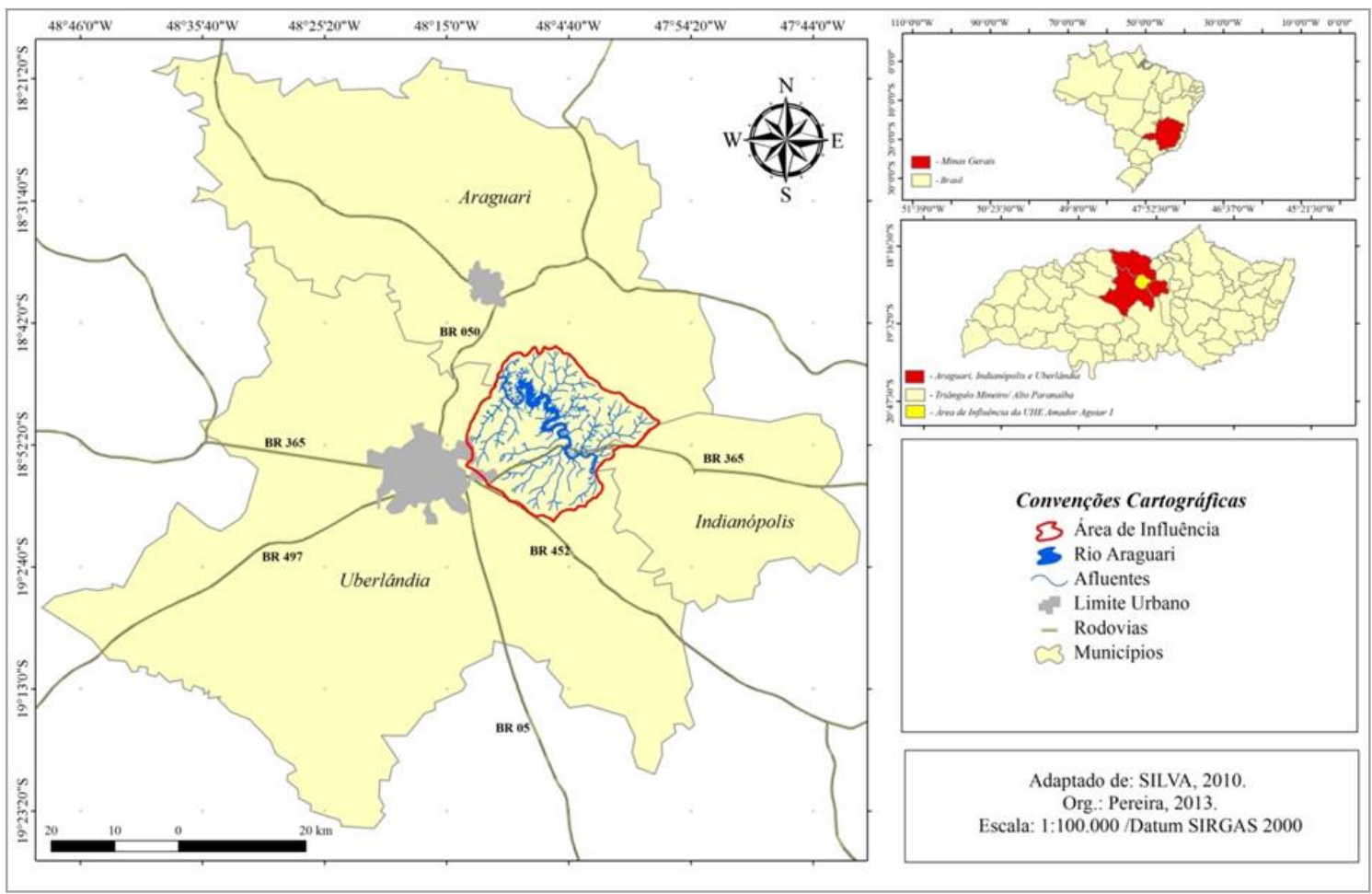

Fonte: Organizado pela autora.

\section{METODOLOGIA}

Inicialmente foi realizada a coleta dos dados pluviométricos no Sistema de Informações Hidrológicas da Agência Nacional de Águas (ANA). Esta plataforma apresenta dados oficiais de chuva, dispostos em banco de dados Access, contendo totais diários, mensais e anuais. Foram também obtidos dados em séries históricas junto ao Laboratório de Climatologia da Universidade Federal de Uberlândia, que dispõe de estação climatológica própria. A seguir está a tabela com as informações referentes às estações pluviométricas (Tabela 1).

Tabela 1: Estações pluviométricas utilizadas para o cálculo da erosividade das chuvas.

\begin{tabular}{ccccccc}
\hline № & Código & Nome & Município & UF & Período & Média Geral \\
\hline $\mathbf{0 1}$ & 01948006 & Fazenda Letreiro & Uberlândia & MG & $1981-2011$ & $1520,8(\mathrm{~mm})$ \\
$\mathbf{0 2}$ & 01947019 & Porto Saracura & Indianópolis & MG & $1978-1996$ & $1426,8(\mathrm{~mm})$ \\
$\mathbf{0 3}$ & 1848010 & Araguari & Araguari & MG & $1981-2011$ & $1492,5(\mathrm{~mm})$ \\
$\mathbf{0 4}$ & 1847001 & Estrela do Sul & Estrela do Sul & MG & $1981-2011$ & $1465,2(\mathrm{~mm})$ \\
$\mathbf{0 5}$ & 1847007 & Cascalho Rico & Cascalho Rico & MG & $1981-2011$ & $1776(\mathrm{~mm})$ \\
$\mathbf{0 6}$ & - & Uberlândia & Uberlândia & MG & $1981-2011$ & $1567,5(\mathrm{~mm})$ \\
\hline
\end{tabular}

Fonte: Estações no 01 a 05 -<http:IVhidroweb.ana.gov.br>. Estação № 06- Laboratório de Climatologia (IG-UFU). Organizado pela autora.

$\mathrm{Na}$ área de influência da UHE-AAI não foram identificadas estações climatológicas em funcionamento e/ou que possuísse registros consistentes de dados. Diante deste fato, foram utilizadas as estações localizadas nas proximidades da área de estudo, totalizando seis estações. Sendo, cinco estações

\begin{tabular}{llllll}
\hline Caminhos de Geografia & Uberlândia - MG & v. 19, n. 68 & Dez/2018 & p. 186-199 Página 188
\end{tabular}


com série histórica de 30 anos, no período de 1981 a 2011 e uma estação com série de 18 anos, compreendendo o período de 1978 a 1996 (Figura 2).

Figura 2: Localização das estações pluviométricas utilizadas no cálculo da erosividade das chuvas.

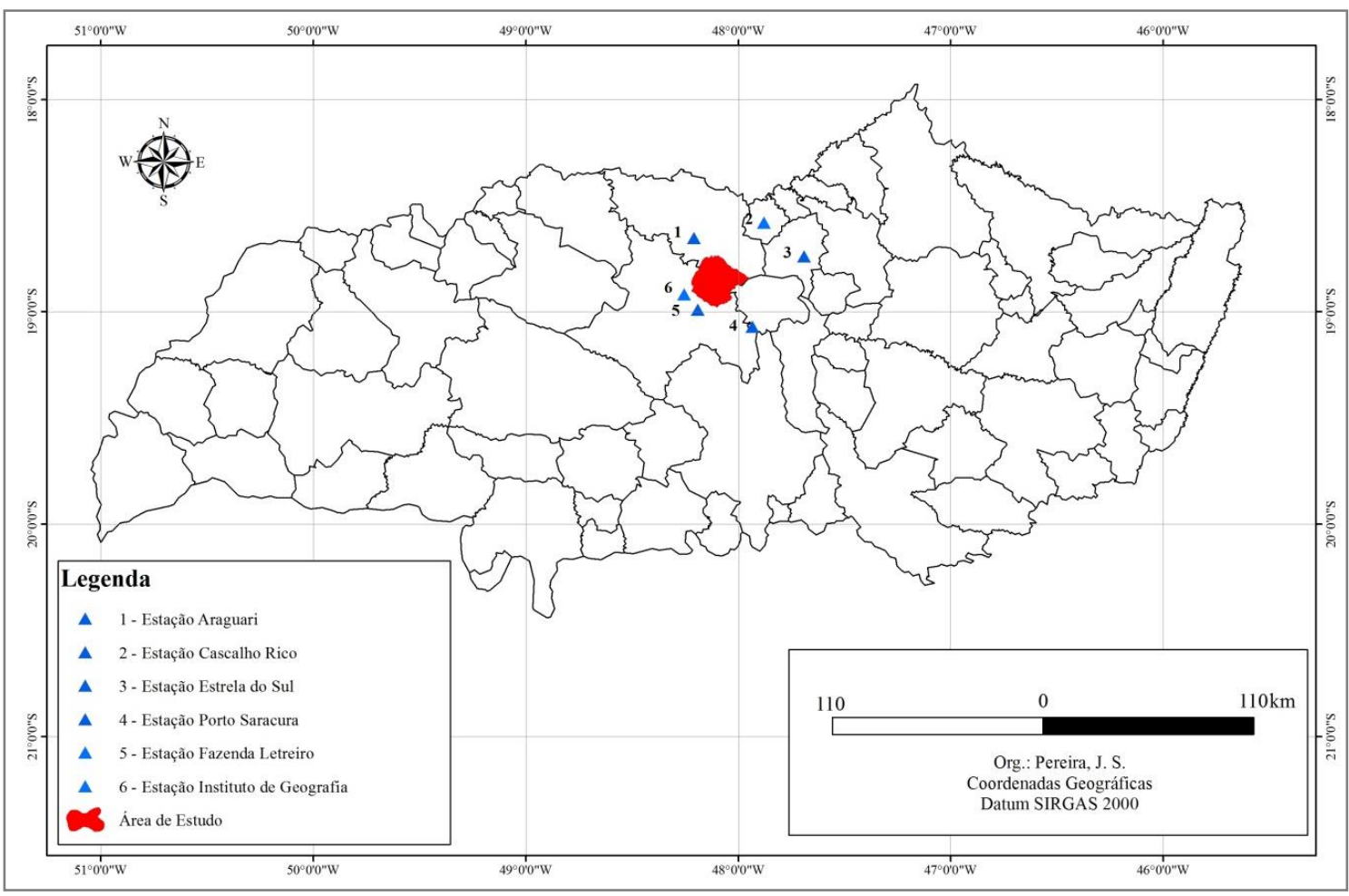

Fonte: Organizado pela autora.

Após a coleta, os dados da precipitação pluvial foram organizados em planilhas do Excel, com a finalidade de facilitar a compreensão do regime pluviométrico, o padrão de distribuição das chuvas e a comparação dos índices de erosividade ao longo dos anos. Nesse sentido, foi elaborado um gráfico contendo as precipitações médias mensais das estações pluviométricas com a sua referente série histórica. Haja vista, que as informações dispostas em forma de gráfico são mais fáceis de serem visualizadas e consequentemente entendidas.

Com os valores da precipitação organizados foi determinado o índice de erosividade anual, Fator R. Entretanto, foram calculados inicialmente os índices de erosividade mensal (EI) de cada estação pluviométrica, utilizando-se da metodologia proposta por Lombardi Neto (1977) apud Nascimento (1998), (Equação 1). Nessa equação são considerados os valores médios e totais da precipitação pluvial.

$\mathrm{El}=89,823\left(\frac{r^{2}}{P}\right)^{0,759}$

El - índice de erosividade média mensal (MJ.mm/ha/h),

$r$ - precipitação média mensal $(\mathrm{mm})$;

$\mathrm{P}$ - precipitação média anual $(\mathrm{mm})$.

Por meio dos índices de erosividade média mensal (EI) foi possível realizar o cálculo da erosividade anual (Fator R), obtido pela somatória das médias mensais do (EI) de cada estação pluviométrica, considerando a série histórica estabelecida (Equação 2). Igualmente aos gráficos, os cálculos dos índices de erosão e erosividade das chuvas, também foram realizados no software Excel 2010.

$\mathrm{R}=\sum \mathrm{EI}$

(2)

$\begin{array}{llllll}\text { Caminhos de Geografia } & \text { Uberlândia - MG } & \text { v. 19, n. 68 } & \text { Dez/2018 } & \text { p. 186-199 } & \text { Página } 189\end{array}$


R - Erosividade anual (MJ.mm/ha.h.ano),
El - índice de erosividade média mensal (MJ.mm/ha.h.mês).

Posteriormente, os valores da erosividade anual foram espacializados através da Krigagem Ordinária, com o uso do módulo Interpolation - Kriging do pacote de aplicativos ArcGis 9.3.1 da ESRI.

A escolha de um modelo de interpolação apropriado é essencial para gerar mapas de espacialização confiáveis. A qualidade da interpolação espacial de dados climáticos é dependente da densidade e da distribuição dos pontos usados no cálculo, além da existência de correlação entre os modelos estatísticos dos interpoladores e os fenômenos em estudo (SILVA et al., 2011).

As várias formas de Krigagem utilizadas no presente estudo resultaram em espacializações peculiares, contudo, não apresentaram variações significativas na distribuição dos dados. Para a espacialização da erosividade na Área de influência da UHE-AAI, foi realizado a Krigagem Ordinária considerando os modelos, Gaussiano, Linear, Esférico, Exponencial, Circular e também a Krigagem Universal, com os modelos Linear e Quadrático. Abaixo está o fluxograma contendo as etapas realizadas para a determinação do Fator $\mathrm{R}$, bem como para a sua espacialização (Figura 3).

Figura 3: Procedimentos operacionais realizados para a determinação do Fator R da USLE.
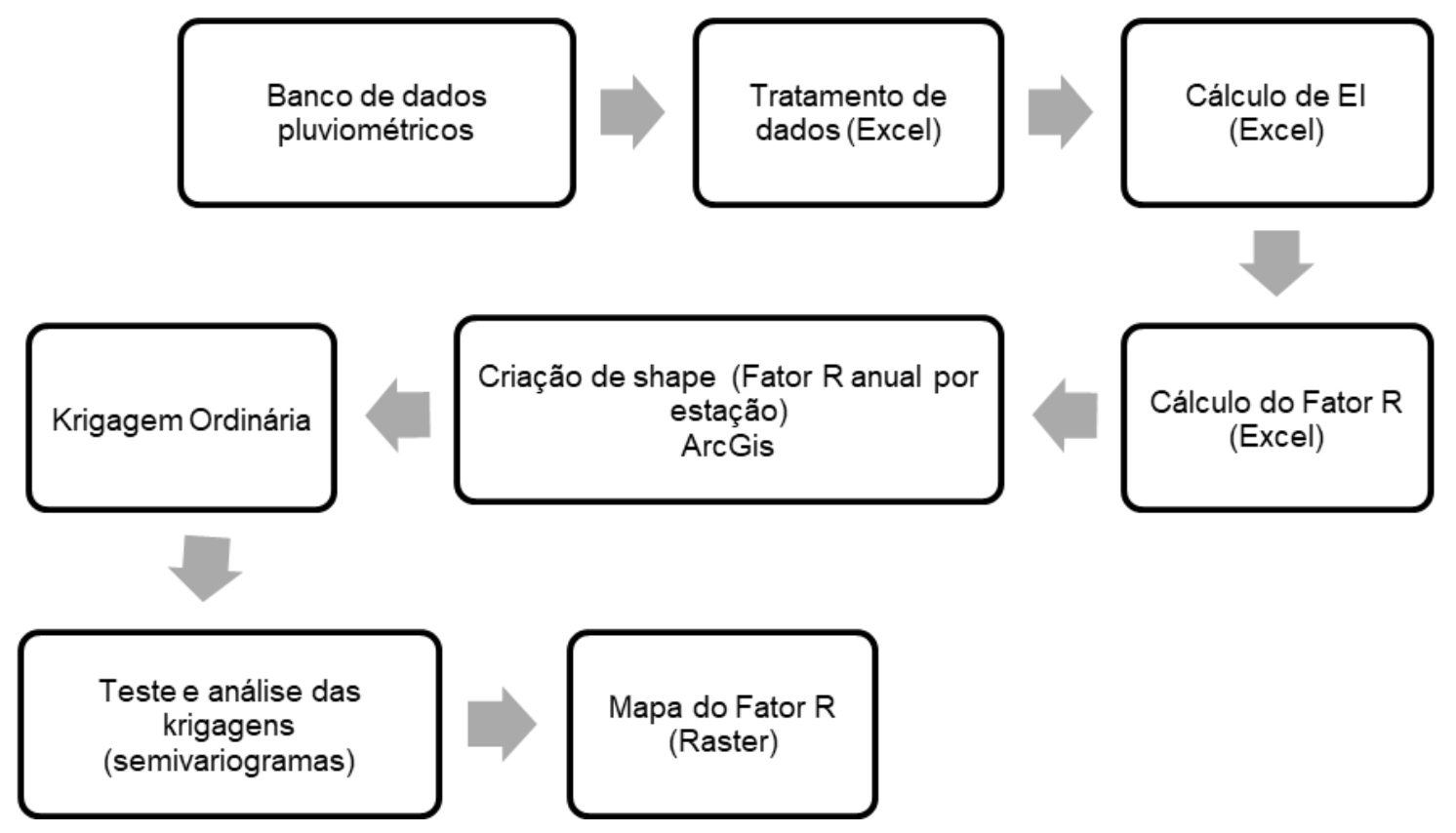

Fonte: Organizado pela autora.

\section{RESULTADOS E DISCUSSÕES}

O método Krigagem foi escolhido por apresentar menores erros de interpolação dos parâmetros avaliados e também por proporcionar uma distribuição mais uniformizada dos dados. Os interpoladores possuem algumas funções interessantes, que permitem uma prévia avaliação dos resultados antes de espacializá-los.

O conhecimento da precipitação pluvial, assim como, a sua distribuição espacial é fundamental no manejo dos recursos hídricos, na conservação dos solos e também na aplicação de modelagem preditiva de erosão laminar (FABRY, 2004; TAO et al., 2009). Este estudo comparou os índices pluviométricos e calculou a erosividade das chuvas na área de influência da UHE-AAI. A análise dos dados de precipitação evidencia a distribuição irregular das chuvas, com máxima concentração no verão e mínima no inverno.

$\begin{array}{llllll}\text { Caminhos de Geografia } & \text { Uberlândia - MG } & \text { v. 19, n. } 68 & \text { Dez/2018 } & \text { p. 186-199 Página } 190\end{array}$


Todas as estações avaliadas indicam que a maior pluviosidade acontece de outubro a março. Essa sazonalidade é característica das regiões tropicais, na qual há duas estações bem definidas, sendo os meses de dezembro e janeiro os de maiores precipitações. Os valores de precipitação no período chuvoso alcançam totais superiores a $1.500 \mathrm{~mm}$, segundo Mello et al., (2003) a região do Triângulo Mineiro e Alto Paranaíba apresentaram os valores pluviométricos elevados e com grande incidência de chuvas erosivas.

A influência da continentalidade nessa região acarreta as diferenças pluviométricas e também de temperaturas, além de elevada amplitude térmica diária e umidade atmosférica com índices baixos entre os meses de maio a agosto. A diferença entre os volumes pluviométricos são significativas, chegando a atingir uma amplitude com variações de mais de $300 \mathrm{~mm}$ entre os meses mais secos e os meses mais chuvosos. Os meses de junho a agosto apresentam os menores valores, não ultrapassando os $25 \mathrm{~mm}$ médios mensais (Figura 4).

Figura 4: Precipitação pluviométrica média mensal.

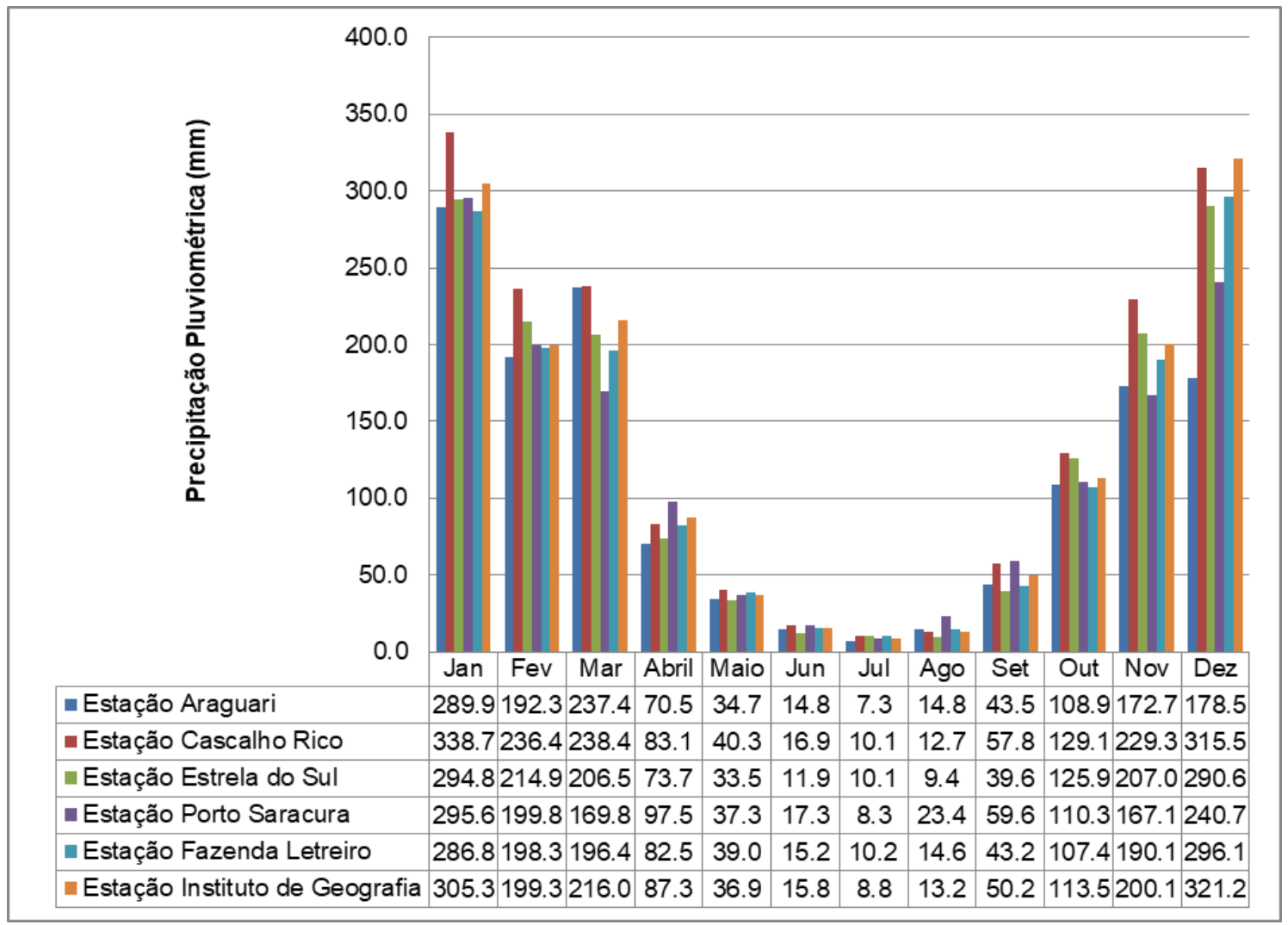

Fonte: <http:IVhidroweb.ana.gov.br> e Laboratório de Climatologia da Universidade Federal de Uberlândia. Organizado pela autora.

No verão, a precipitação pluvial sobrevém de forma mais acentuada, particularidade das chuvas convectivas, que ocorrem de maneira intensa e em curto período de duração. É justamente neste período, que os solos são preparados para os diferentes cultivos, sendo imprescindível planejar o manejo dos plantios com intuito de impedir que os solos estejam desprotegidos durante os períodos com maior incidência das chuvas.

Verificou-se uma amplitude geral de $2.718 \mathrm{~mm}$ para os totais anuais de precipitação, com o valor mínimo de precipitação pluviométrica de 581,1 mm, registrado em 1996 na estação Porto Saracura, e máximo de 3299,1 mm, registrado em 1987 na estação Cascalho Rico (Tabela 2). 
Tabela 2: Totais pluviométricos $(\mathrm{mm})$ anuais entre 1978 e 2011.

\begin{tabular}{|c|c|c|c|c|c|c|}
\hline Ano & $\begin{array}{c}\text { Porto } \\
\text { Saracura }\end{array}$ & Araguari & $\begin{array}{l}\text { Cascalho } \\
\text { Rico }\end{array}$ & $\begin{array}{l}\text { Estrela } \\
\text { do Sul }\end{array}$ & $\begin{array}{l}\text { Fazenda } \\
\text { Letreiro }\end{array}$ & $\begin{array}{c}\text { Instituto de } \\
\text { Geografia }\end{array}$ \\
\hline 1978 & 1874,8 & - & - & - & - & - \\
\hline 1979 & 1630,5 & - & - & - & - & - \\
\hline 1980 & 1118,5 & - & - & - & - & - \\
\hline 1981 & 922 & 1600,6 & 1455,8 & 1406,7 & 1326,3 & 1503,6 \\
\hline 1982 & 1461,3 & 1891,3 & 1622,4 & 1724,9 & 1845,9 & 2207,1 \\
\hline 1983 & 2489,4 & 1812,1 & 2013,7 & 2484,4 & 1875,9 & 1963 \\
\hline 1984 & 1336,3 & 1043,3 & 1026,9 & 1177,6 & 1273,9 & 1278 \\
\hline 1985 & 1479,2 & 1518,8 & 1579,1 & 1394,5 & 1200,2 & 1572,7 \\
\hline 1986 & 1559,7 & 1483,8 & 1304,7 & 1352,4 & 1312,9 & 1555,1 \\
\hline 1987 & 2003,1 & 1476,5 & 3299,1 & 1428,4 & 1587,5 & 1477,2 \\
\hline 1988 & 1248 & 1356,4 & 3153 & 1388,6 & 998,8 & 1514,5 \\
\hline 1989 & 922 & 1582,1 & 3237,8 & 1879,7 & 1516,9 & 1406,5 \\
\hline 1990 & 1366 & 1266,4 & 2089,7 & 1012,8 & 1096,1 & 1012,6 \\
\hline 1991 & 1871,1 & 2256,4 & 2994 & 1583,4 & 1273,8 & 1782 \\
\hline 1992 & 2097 & 1555,7 & 2047,6 & 1884,1 & 2059,9 & 1969,5 \\
\hline 1993 & 1657,3 & 1034,4 & 1710,5 & 1211,8 & 1543,4 & 1642 \\
\hline 1994 & 757,1 & 1615,4 & 1708 & 1438,2 & 1284,4 & 1621,4 \\
\hline 1995 & 734,1 & 1261,3 & 2118,6 & 1689,8 & 1462,9 & 1662,1 \\
\hline 1996 & 581,1 & 1650,3 & 1412 & 1225,8 & 1219,2 & 1443,7 \\
\hline 1997 & - & 1446,2 & 1528,8 & 1409,4 & 1671,4 & 1814,2 \\
\hline 1998 & - & 1094,9 & 1221,8 & 982,7 & 1231,9 & 1313,7 \\
\hline 1999 & - & 1179,1 & 1304,7 & 1200,2 & 1274,4 & 1284 \\
\hline 2000 & - & 1781,9 & 1893,1 & 1742,4 & 1547,9 & 1828,7 \\
\hline 2001 & - & 1646,2 & 1367,3 & 1367,2 & 1461,6 & 1428,6 \\
\hline 2002 & - & 1446,7 & 1305,2 & 1367,3 & 1431,4 & 1485,1 \\
\hline 2003 & - & 1390 & 1599,6 & 1822,6 & 1937,7 & 1646,5 \\
\hline 2004 & - & 1346,5 & 1556,6 & 1538,2 & 1437,7 & 1555,4 \\
\hline 2005 & - & 1788,1 & 2005,1 & 1327,7 & 1565,3 & 1453,3 \\
\hline 2006 & - & 1414,76 & 1622,8 & 1464,9 & 2284,6 & 1864,3 \\
\hline 2007 & - & 1389 & 1053,1 & 1193,1 & 1626 & 1531,6 \\
\hline 2008 & - & 1557,5 & 1595,8 & 1671,7 & 1749,7 & 1701,4 \\
\hline 2009 & - & 1695,8 & 1177,3 & 1323,8 & 2076,6 & 1388,6 \\
\hline 2010 & - & 1273,8 & 1242,2 & 1335,5 & 1287,2 & 1258,2 \\
\hline 2011 & - & 1411,8 & 1811,2 & 1390,8 & 1684 & 1426,4 \\
\hline Máx ${ }^{(1)}$ & 2489,4 & 2256,4 & 3299,1 & 2484,4 & 2284,6 & 2207,1 \\
\hline $\operatorname{Min} .{ }^{(2)}$ & 581,1 & 1034,4 & 1026,9 & 982,7 & 998,8 & 1012,6 \\
\hline Média. ${ }^{(3)}$ & 1426,8 & 1492,5 & 1776,0 & 1465,2 & 1520,8 & 1567,5 \\
\hline Dp..$^{(4)}$ & 511,9 & 261,3 & 622,4 & 298,3 & 307,4 & 245,8 \\
\hline Cv.(\%) ${ }^{(5)}$ & 35,8 & 17,5 & 35,0 & 20,3 & 20,2 & 15,7 \\
\hline Amp. ${ }^{(6)}$ & 1908,3 & 1222 & 2272,2 & 1501,7 & 1285,8 & 1194,5 \\
\hline
\end{tabular}

Estatísticas dos dados pluviométricos. ${ }^{(1)}$ Valor Máximo; ${ }^{(2)}$ Valor Mínimo; ${ }^{(3)}$ Média; ${ }^{(4)}$ Desvio Padrão; ${ }^{(5)}$ Coeficiente de Variação; ${ }^{(6)}$ Amplitude. Fonte: Hidroweb, Agência nacional de águas, 2013 e Laboratório de Climatologia da Universidade Federal de Uberlândia, Organizado pela autora. 
É sabido que a distribuição dos valores médios de erosividade está intimamente relacionada à precipitação, já que seu cálculo baseia-se nas médias anuais e mensais dos totais pluviométricos. Nesse sentido, a erosividade é bastante elevada nos meses mais chuvosos, principalmente dezembro e janeiro. O mês de outubro apresenta a menor erosividade em comparação aos outros meses do mesmo período da estação.

No mês de Julho ocorrem precipitações mínimas, e, por conseguinte são estabelecidos os menores índices de erosividade, visto que, nesse mês dificilmente ocorrem precipitações intensas e sequenciais, todos esses aspectos são intrínsecos ao período de inverno.

O gráfico a seguir demonstra erosividade média (EI), das estações pluviométricas de 1981 a 2011. Como já mencionado anteriormente, somente a estação Porto Saracura não contempla a série histórica de 30 anos, sendo considerados 18 anos (Figura 5).

Figura 5: Erosividade média por estação pluviométrica.

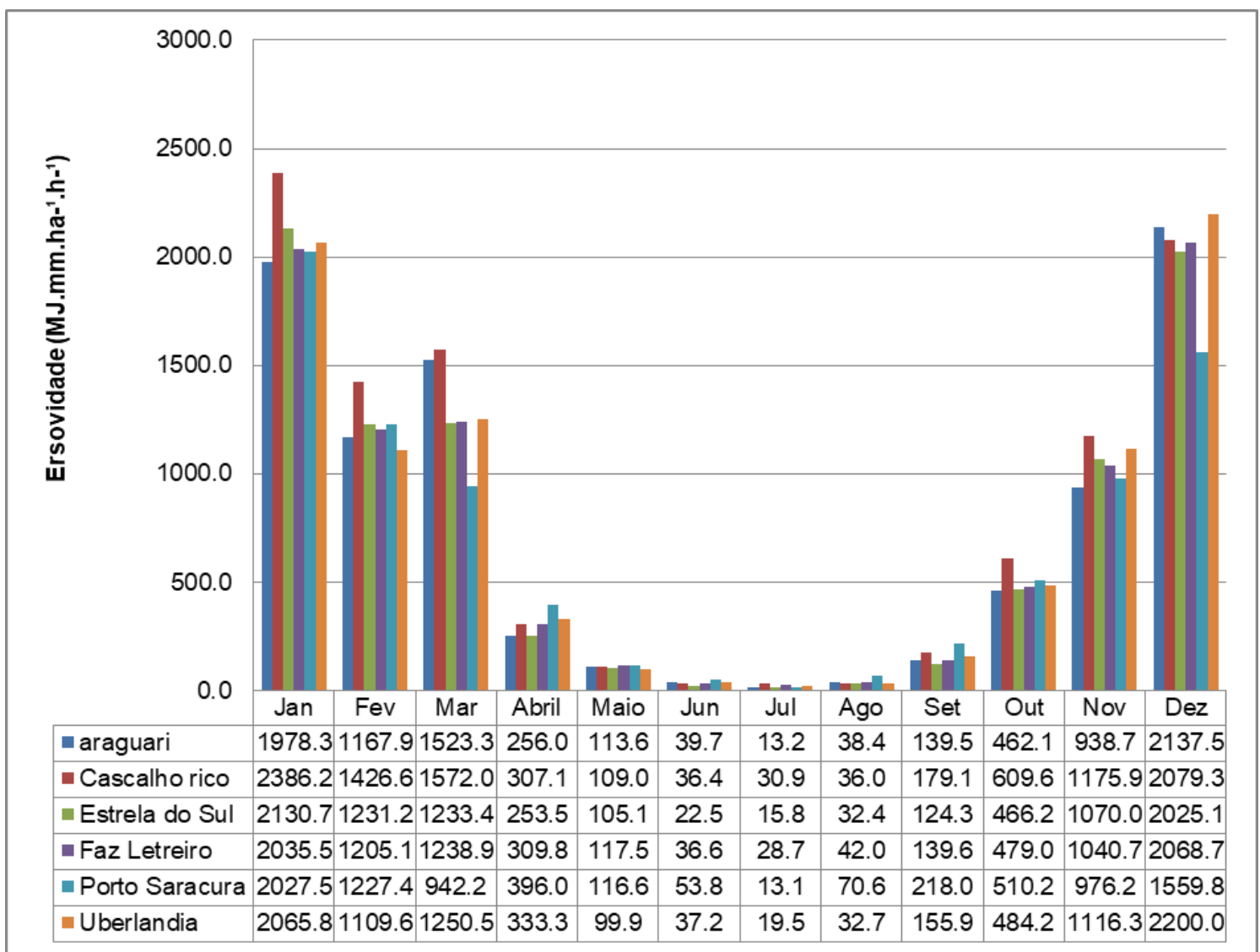

Fonte: <http:|\hidroweb.ana.gov.br> e Laboratório de Climatologia da Universidade Federal de Uberlândia. Organizado pela autora.

A maior erosividade mensal foi de 2386,2 MJ. mm.ha ${ }^{-1} \mathrm{mês}^{-1}$, expressa pela estação Cascalho Rico no mês de janeiro, já a menor foi de $13,1 \mathrm{MJ} . \mathrm{mm} \cdot \mathrm{ha}^{-1} \mathrm{mês}^{-1}$, registrada pela estação Porto Saracura, em julho. Dessa forma, é menor o risco de perda de solo por erosão laminar no período do inverno. $O$ valor médio anual da erosividade (Fator R) encontrado foi de $8881,9 \mathrm{MJ} . \mathrm{mm}_{\text {.ha }}{ }^{-1}$ ano ${ }^{-1}$, com variação de 4911,6 a 15192,9 MJ.mm.ha ${ }^{-1}$ ano $^{-1}$ (Tabela 3). 
Tabela 3: Erosividade anual (MJ.mm.ha-1. h $^{-1}$ ) por estação pluviométrica.

\begin{tabular}{|c|c|c|c|c|c|c|}
\hline Ano & $\begin{array}{c}\text { Porto } \\
\text { Saracura }\end{array}$ & Araguari & $\begin{array}{l}\text { Cascalho } \\
\text { Rico }\end{array}$ & $\begin{array}{l}\text { Estrela } \\
\text { do Sul }\end{array}$ & $\begin{array}{l}\text { Fazenda } \\
\text { Letreiro }\end{array}$ & $\begin{array}{c}\text { Instituto de } \\
\text { Geografia }\end{array}$ \\
\hline 1978 & 9205,2 & - & - & - & - & - \\
\hline 1979 & 9162,5 & - & - & - & - & - \\
\hline 1980 & 6675,6 & - & - & - & - & - \\
\hline 1981 & 6433,3 & 9246,1 & 9302,0 & 8418,5 & 8126,0 & 9051,0 \\
\hline 1982 & 8978,2 & 10429,8 & 10590,0 & 10955,6 & 10331,1 & 11568,9 \\
\hline 1983 & 13202,4 & 10103,7 & 10896,1 & 11977,6 & 9402,3 & 9704,9 \\
\hline 1984 & 7171,1 & 6073,7 & 6322,3 & 6650,5 & 7034,6 & 7269,9 \\
\hline 1985 & 9181,9 & 9827,4 & 10233,3 & 9748,0 & 8419,1 & 10202,1 \\
\hline 1986 & 8963,8 & 8883,6 & 7768,5 & 8133,1 & 8054,9 & 9258,2 \\
\hline 1987 & 10825,2 & 8827,5 & 14766,0 & 7858,6 & 8831,2 & 8528,6 \\
\hline 1988 & 7409,8 & 8003,3 & 13889,3 & 8407,1 & 7032,2 & 8366,5 \\
\hline 1989 & 6433,3 & 9274,3 & 14287,0 & 10589,6 & 8495,0 & 8129,1 \\
\hline 1990 & 6838,2 & 7286,3 & 9323,4 & 6062,7 & 5798,0 & 5498,9 \\
\hline 1991 & 10244,6 & 12652,6 & 15192,9 & 9265,9 & 8023,8 & 10345,9 \\
\hline 1992 & 10819,3 & 8278,6 & 11131,2 & 10498,7 & 10350,8 & 10459,6 \\
\hline 1993 & 8632,9 & 6706,0 & 9344,5 & 8234,4 & 8805,2 & 8757,4 \\
\hline 1994 & 5422,2 & 11204,8 & 9760,6 & 9035,4 & 8090,8 & 9656,5 \\
\hline 1995 & 4980,7 & 7562,8 & 11696,2 & 9097,3 & 8999,6 & 9510,6 \\
\hline 1996 & 4911,6 & 8510,0 & 7652,5 & 6734,5 & 6951,1 & 8054,3 \\
\hline 1997 & - & 8352,9 & 8989,2 & 8085,1 & 9350,9 & 9601,6 \\
\hline 1998 & - & 6535,0 & 7046,9 & 6100,4 & 6792,6 & 7234,2 \\
\hline 1999 & - & 7638,8 & 8280,4 & 7813,3 & 7792,5 & 7692,8 \\
\hline 2000 & - & 9879,3 & 10633,6 & 9880,9 & 8823,1 & 10569,4 \\
\hline 2001 & - & 9010,8 & 8138,9 & 8900,9 & 8808,5 & 8120,9 \\
\hline 2002 & - & 9031,6 & 8475,4 & 8772,6 & 9237,5 & 9088,6 \\
\hline 2003 & - & 8757,1 & 9539,0 & 11042,3 & 11593,1 & 10019,0 \\
\hline 2004 & - & 8257,7 & 9836,0 & 9379,9 & 8877,1 & 8741,8 \\
\hline 2005 & - & 11537,4 & 13049,8 & 8062,8 & 9049,3 & 8903,2 \\
\hline 2006 & - & 8054,1 & 9134,4 & 8280,0 & 11330,9 & 9856,8 \\
\hline 2007 & - & 7980,6 & 7186,5 & 7860,7 & 9526,8 & 9274,9 \\
\hline 2008 & - & 9041,6 & 9398,3 & 9692,2 & 9327,1 & 9236,2 \\
\hline 2009 & - & 8671,9 & 7050,4 & 7514,1 & 10148,0 & 7697,4 \\
\hline 2010 & - & 8298,3 & 7965,6 & 8184,8 & 7958,9 & 7395,6 \\
\hline 2011 & - & 8954,8 & 11512,3 & 8776,8 & 9644,1 & 8257,3 \\
\hline Máx ${ }^{(1)}$ & 13202,4 & 12652,6 & 15192,9 & 11977,6 & 11593,1 & 11568,9 \\
\hline $\operatorname{Min}^{(2)}$ & 4911,6 & 6073,7 & 6322,3 & 6062,7 & 5798,0 & 5498,9 \\
\hline Média. ${ }^{(0)}$ & 8183,8 & 8802,3 & 9948,1 & 8710,1 & 8742,1 & 8904,9 \\
\hline Dp. ${ }^{(4)}$ & 2213,9 & 1419,0 & 2355,8 & 1414,3 & 1290,1 & 1235,4 \\
\hline Cv.(\%) & 27,1 & 16,1 & 23,7 & 16,2 & 14,8 & 13,9 \\
\hline Amp. ${ }^{(6)}$ & 8290,8 & 6578,9 & 8870,5 & 5914,9 & 5795,0 & 6070,0 \\
\hline
\end{tabular}

Estatísticas dos dados de erosividade da chuva. ${ }^{(1)}$ Valor Máximo; ${ }^{\left({ }^{2}\right)}$ Valor Mínimo; ${ }^{(3)}$ Média; ${ }^{(4)}$ Desvio Padrão;

${ }^{(5)}$ Coeficiente de Variação; ${ }^{(6)}$ Amplitude. Fonte: Hidroweb, Agencia nacional de águas, 2013 e Laboratório de Climatologia da Universidade Federal de Uberlândia, Organizado pela autora. 
Muitos estudos sobre a determinação dos índices erosivos têm sido realizados no Brasil, com o intuito de melhor conhecer o comportamento da precipitação frente ao desenvolvimento dos processos erosivos e também estabelecer uma relativa padronização dos valores encontrados para as mais diversas localidades. Nesse sentido, são estabelecidos agrupamentos dos valores de erosividade das chuvas e atribuído qualificações para os mesmos.

Beltrame (1994) qualificou os valores da erosividade das chuvas mensais em cinco classes, respectivamente: erosividade débil; média; forte; muito forte e erosividade excessiva (Tabela 4).

Tabela 4: Classificação da erosividade das chuvas de acordo com Beltrame (1994).

\begin{tabular}{cc}
\hline Classes (MJ.mm.ha ${ }^{-1}$ mês $\left.^{-1}\right)$ & Qualificação \\
\hline$<599,04$ & Erosividade débil \\
599,04 a 675,48 & Erosividade média \\
675,49 a 751,91 & Erosividade forte \\
751,91 a 828,33 & Erosividade muito forte \\
$>828,33$ & Erosividade excessiva \\
\hline
\end{tabular}

Fonte: BELTRAME (1994). Organizado pela autora.

Considerando que a média anual da erosividade para a área de estudo é de aproximadamente $8881,9 \mathrm{MJ} \cdot \mathrm{mm} \cdot \mathrm{ha}^{-1} \mathrm{ano}^{-1}$, os valores alcançados no período chuvoso são preocupantes, alcançando 2386,2 MJ.mm.ha ${ }^{-1}$ mês $^{-1}$, somente em janeiro. Diante o exposto, é percebido na área de influência da UHE-AAI, à atuação da erosividade débil no período de estiagem e erosividade excessiva no período chuvoso.

Os valores de erosividade acima de $8000 \mathrm{MJ} \cdot \mathrm{mm} \mathrm{ha}^{-1} \mathrm{ano}^{-1}$, são considerados elevados de acordo com Mello et., al (2007), e merecem maior atenção. Embora, a erosividade se constitua em mais um dos fatores responsáveis pelo desencadeamento dos processos erosivos, é preciso ter uma visão integradora desse fenômeno, considerando todas as variáveis que exercem influência, para nesta circunstância, estabelecer técnicas preventivas ou mesmo mitigadoras da erosão.

Fundamentado nos estudos de Foster et al., (1981), Mello et al., (2007) realizaram um zoneamento do estado de Minas Gerais diferenciando-o em regiões específicas quanto ao comportamento anual da erosividade. Os autores afirmam que a região leste, o Triângulo Mineiro e o Alto Paranaíba apresentam os maiores valores de chuvas intensas, sendo que, a erosividade anual média no estado mineiro varia de 5.000 a mais de $12.000 \mathrm{MJ} \cdot \mathrm{mm} \cdot \mathrm{ha}^{-1} \mathrm{ano}^{-1}$, com total anual de precipitação variando entre 800 e $1.700 \mathrm{~mm}$ (Tabela 5).

Tabela 5: Erosividade média anual para o Estado de Minas Gerais.

\begin{tabular}{ccc}
\hline $\begin{array}{c}\text { Erosividade } \\
\left(\mathrm{Mj} . \mathrm{mm}_{\mathrm{ha}} \mathrm{ano}^{-1}\right)\end{array}$ & Qualificação & Região de Influência \\
\hline $4.905-7.357$ & $\begin{array}{c}\text { Erosividade } \\
\text { média a alta }\end{array}$ & $\begin{array}{c}\text { Região central; parte da Zona da Mata mineira; região Sul e } \\
\text { Nordeste de Minas Gerais. }\end{array}$ \\
$7.357-9.810$ & $\begin{array}{c}\text { Erosividade alta } \\
\text { Triângulo Mineiro e Noroeste do Estado; partes do Centro- } \\
\text { norte de Minas e do Sul de Minas Gerais. }\end{array}$ \\
$\begin{array}{c}\text { Erosividade } \\
\text { muito alta }\end{array}$ & $\begin{array}{c}\text { Parte do Alto Paranaíba; leste e região do entorno da Serra } \\
\text { da Mantiqueira. }\end{array}$ \\
\hline
\end{tabular}

Fonte: MELLO et al.,(2007).Org. Organizado pela autora. 
Embora as diferentes estações pluviométricas estejam localizadas em áreas distintas no estado de Minas Gerais, os resultados dos índices de erosividade estimados pelos autores podem ser estendidos para à Área de Influência da UHE-AAI. Nessa perspectiva, 83\% dos índices de erosividade são maiores que $7357 \mathrm{Mj} . \mathrm{mm}_{\text {.ha }}{ }^{-1}$ ano-1 assim, é possível classificar os valores de erosividade estimados para a área de estudo como erosividade alta e muito alta.

Observando a figura a seguir é percebido que na Krigagem Universal tanto o modelo Linear, quanto o modelo Quadrático não apresenta variações de espacialização. Também não é visualizada grande dessemelhança entre as formas de Krigagem Ordinária, em ambos os modelos às faixas de erosividade apresentam relativa homogeneidade no que tange a sua distribuição espacial. (Figura 6).

De acordo com a literatura, as medidas de tendência central, como a média e a mediana, também são recursos utilizados para a avaliação da distribuição da variável em estudo, quanto mais próximos esses valores se encontrarem mais uniforme é a espacialização. Para a área de Influência da UHEAAl os valores são respectivamente: 8881,9 (média) e 8772,2 (mediana), sendo observada uma distância entre esses valores de 109,7, embora, os valores não estejam muito distantes, a espacialização não pode ser considerada uniforme.

Figura 6 - Seleção dos mapas pluviométricos produzidos por diferentes modelos de Krigagem.

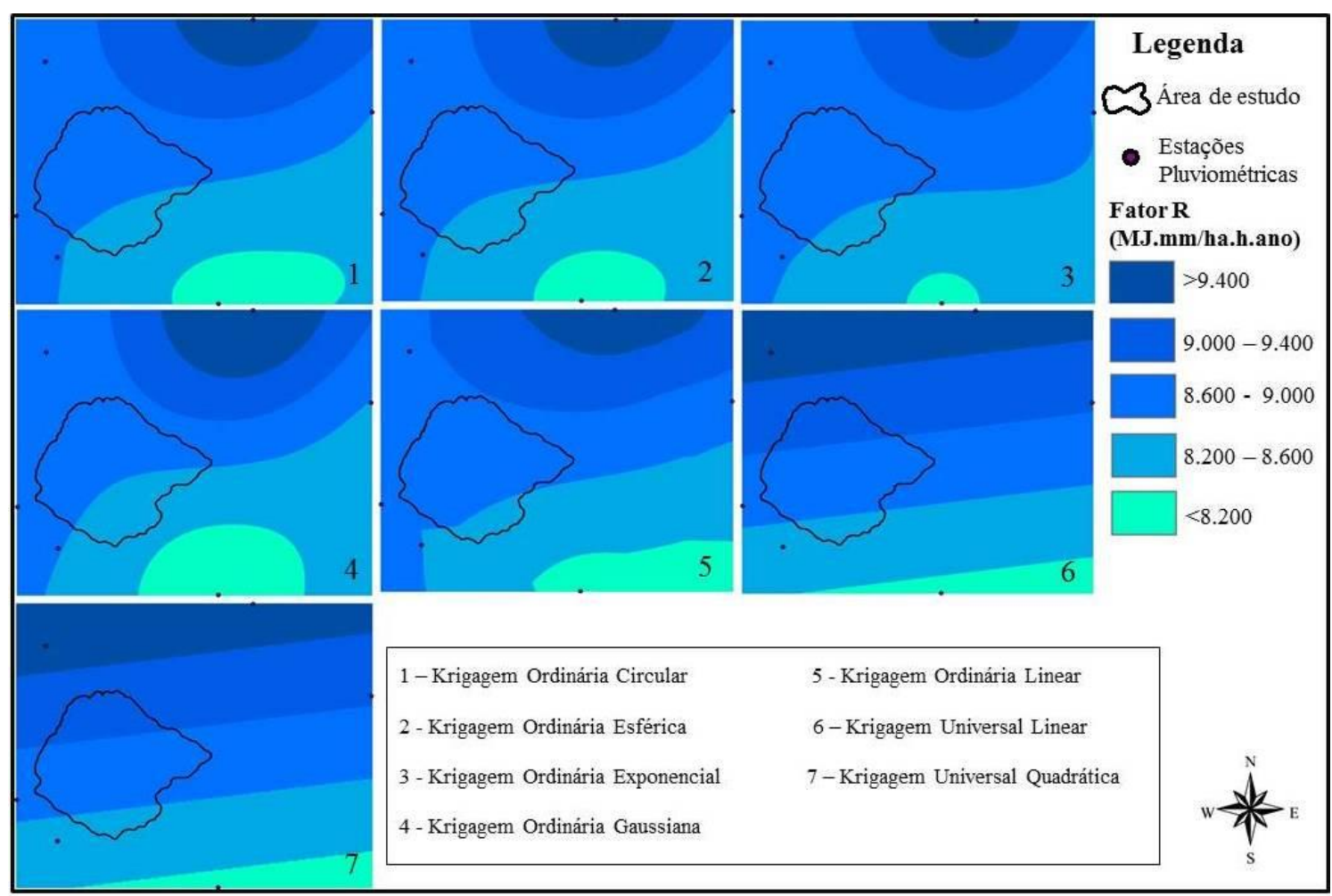

Fonte: Organizado pela autora.

O histograma abaixo elucida que a distribuição da erosividade das chuvas é levemente alongada à direita. Neste caso, a distribuição não é classificada como simétrica, e sim positivamente assimétrica, ocasionada pela diferença entre a média e a mediana (Figura 7).

Considerando que as estações pluviométricas estão em diferentes localizações e que a Krigagem estima valores ainda não amostrados é esperado que a espacialização apresentasse uma distribuição relativamente desigual, até porque os valores da erosividade são diferentes para cada estação. 
Figura 7: Histograma da distribuição da precipitação pluviométrica.

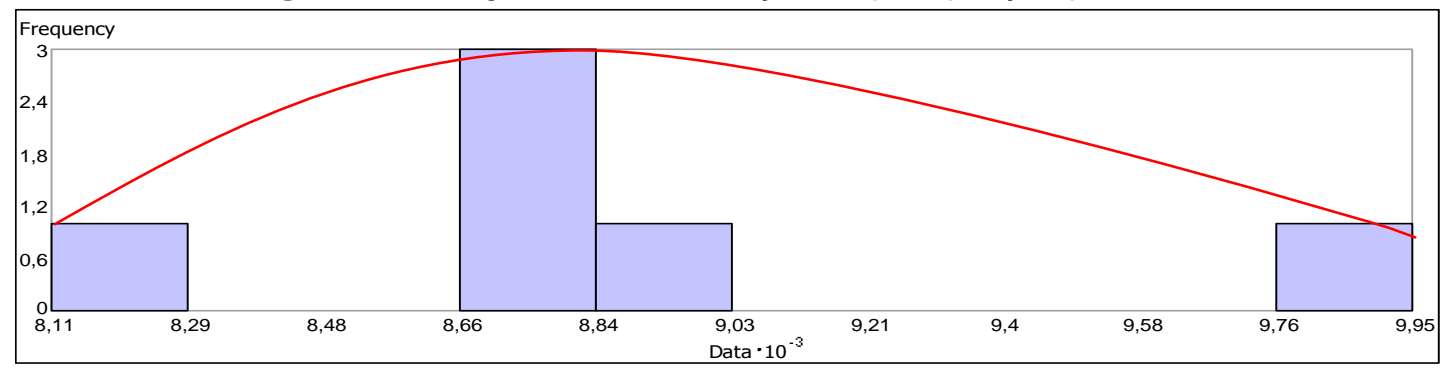

Fonte: Organizado pela autora.

Por mais que o método em questão exclua o caráter tendencioso, ainda é bastante dependente da variabilidade espacial, não obstante, possui como atributo o controle parcial do erro aleatório, capaz de produzir resultados satisfatórios, condizente com espacialização da precipitação observada.

Foi escolhido o modelo de Krigagem Ordinária Linear para representar o índice de erosividade da chuva na Área de Influência da UHE-AAI, principalmente por não constituir formas perfeitamente simétricas ao redor das estações pluviométricas.

$\mathrm{Na}$ área de estudo os valores médios anuais de 8200 a 9000 Mj.mm.ha ${ }^{-1}$ ano $^{-1}$ são predominantes e a distribuição espacial da erosividade é composta de valores mais elevados para as faixas que cortam de noroeste a leste (Figura 8).

Figura 8: Distribuição da erosividade anual na área de estudo.

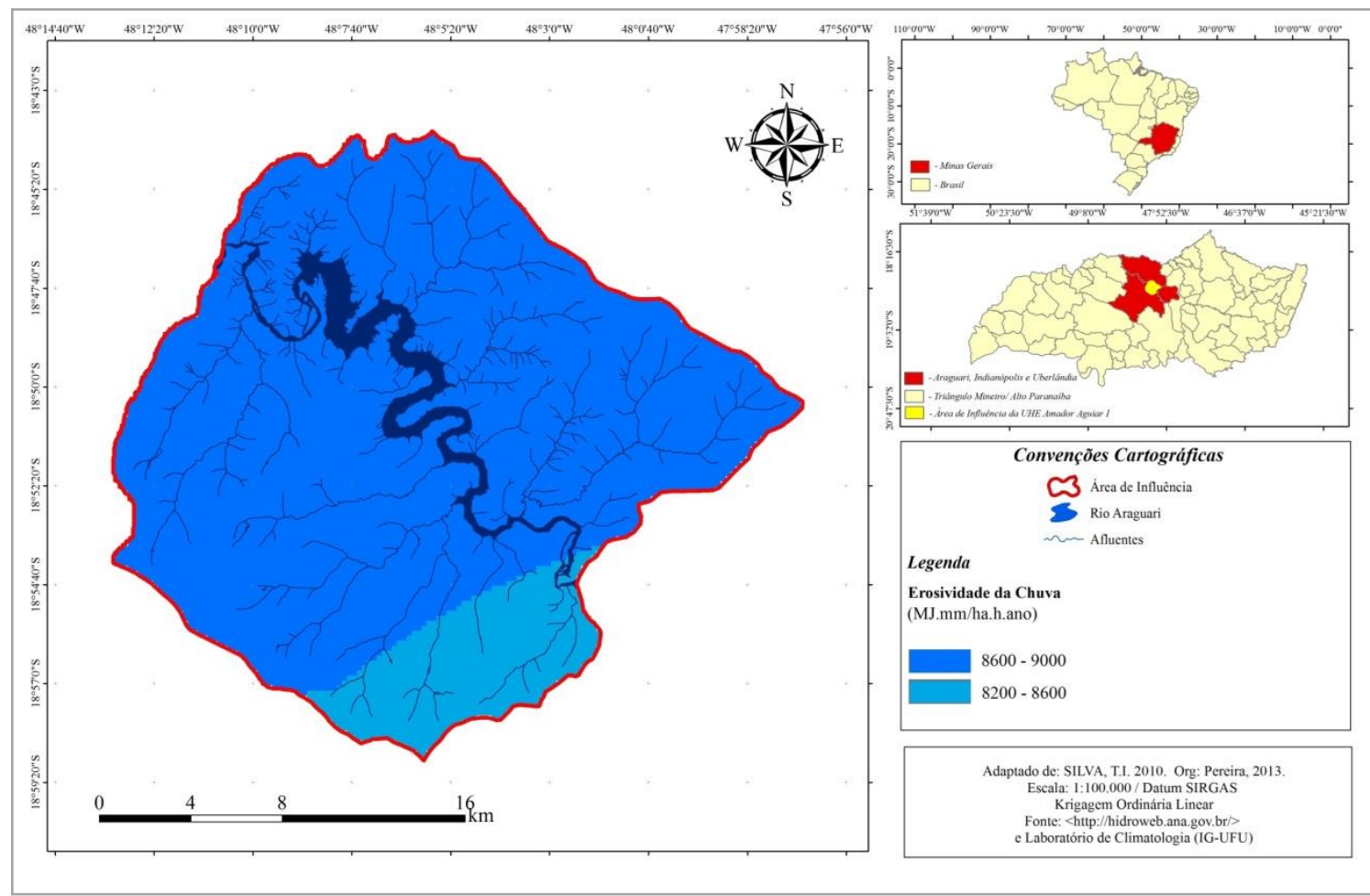

Fonte: Organizado pela autora.

Conforme Mello et al., (2007), o efeito orográfico e as características climáticas específicas de cada região são responsáveis por determinar o comportamento espacial da erosividade nas diversas localidades do estado de Minas Gerais. Os maiores valores de erosividade das chuvas coincide com as médias elevadas de precipitação das estações situadas em áreas com altitudes elevadas, como a estações de Uberlândia, Cascalho Rico e Araguari.

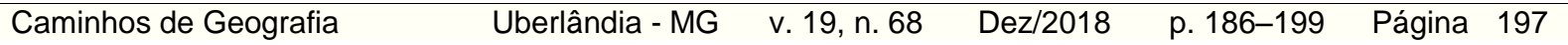


Outro aspecto observado, diz respeito à escolha das estações pluviométricas consideradas na análise dos dados de precipitação. A princípio para a análise da distribuição da erosividade na Área de Influência da UHE-AAI foram escolhidas aproximadamente 13 estações, localizadas em diferentes munícipios do Triangulo Mineiro e com equidistâncias variadas em relação à área de estudo.

As análises iniciais dos dados pluviométricos apresentaram maior variabilidade no que tange a espacialização dos dados e também maiores desvios padrão e variância, o que pode estar diretamente relacionado às próprias diferenças de altitude das estações. Nesse sentido é necessário nos estudos de distribuição da precipitação e/ou erosividade das chuvas, ter cautela na escolha das estações a serem utilizadas, visto que, uma avaliação muito generalizada pode superestimar as informações e consequentemente tornar as avaliações mais complicadas e menos fidedignas com a realidade vigente.

\section{CONSIDERAÇÕES FINAIS}

O potencial da chuva em causar erosão é avaliado através da erosividade. No Brasil há poucos estudos sobre as características físicas das precipitações, e os que existem evidenciam um número reduzido de anos avaliados. E a implantação de pluviógrafos no país ainda é muito recente, não possibilitando uma análise mais aprofundada das variáveis climáticas, uma vez que, possui curta série histórica.

De acordo com a literatura é necessário considerar de 20 a 30 anos consecutivos de monitoramento, para afirmar com veemência as variações temporais e espaciais das precipitações, e neste âmbito conseguir maior precisão e confiabilidade nos dados da erosividade das chuvas para a área analisada.

No entanto, os estudos fundamentados no uso dos pluviômetros têm se mostrado relativamente satisfatórios, permitindo a determinação da erosividade das chuvas para as diferentes localidades brasileiras. A grande importância do conhecimento dos valores da erosividade ao longo dos anos possibilita o melhor planejamento das práticas conservacionistas em virtude dos períodos mais críticos ligados à erosão dos solos.

Na região em que se encontra a UHE Amador Aguiar I, o período crítico em relação à erosão, devido à ocorrência de chuvas erosivas na área, é de novembro a março, é justamente nessa época que devem ocorrer às perdas mais significativas de solo por erosão laminar.

No que diz respeito às técnicas de interpolação a Krigagem ordinária mostrou-se promissora para o mapeamento da erosividade das chuvas, contudo é necessário considerar a quantidades de informação utilizada, uma vez que, quanto maior o volume de informações melhor será a interpolação realizada pelo software e consequentemente os resultados gerados.

\section{AGRADECIMENTOS}

Agradecemos ao CNPQ Proj. PQ 302654/2015-1 pelo apoio financeiro na elaboração desta pesquisa.

\section{REFERÊNCIAS}

AMORIM, S.S.R.; SILVA, D. D. da.; PRUSKI,F.F. Principais modelos para estimar as perdas de solos em áreas agrícolas. In: PRUSKI, F.F. Conservação de solo e água: Práticas mecânicas para o controle da erosão hídrica. 2ed. Viçosa, ed. UFV, 2009. p. 74-107.

BELTRAME, A.V. Diagnóstico do Meio físico de Bacias hidrográficas: modelo e aplicações. Florianopolis: Ed. da UFSC, 1994.

BERTONI, J; LOMBARDI NETO, F. Conservação do solo. 8ª edição. São Paulo: Ícone, 2012, 335 p.

CHUQUIPIONDO, I. G. V. Avaliação da estimativa do potencial de Erodibilidade de solos nas margens de Cursos de água: estudo de caso Trecho de Vazão Reduzida Capim Branco I - Araguari Minas Gerais. 2007. 216 f. Dissertação (Mestrado em Meio Ambiente) - Programa de Pós-graduação em Saneamento, Meio Ambiente e Recursos Hídricos, Universidade Federal de Minas Gerais, Belo Horizonte, 2007. Disponível em: <http://www.smarh.eng.ufmg.br/defesas/265M.PDF> Acesso em 13 de jun. 2013.

FABRY F. Meteorological value of ground target measurements by radar. Journal of Atmospheric and Oceanic Technology 2004; $21: 560-573$. <http://journals.ametsoc.org/doi/pdf/10.1175/15200426\%282004\%29021\%3C0560\%3AMVOGTM\%3E2.0.CO\%3B2>Acesso em 12 de jan. 2013.

$\begin{array}{llllll}\text { Caminhos de Geografia } & \text { Uberlândia - MG } & \text { v. 19, n. 68 } & \text { Dez/2018 } & \text { p. 186-199 Página } 198\end{array}$


LEPSCH, I. F. Formação e Conservação dos Solos. 2.ed.Oficina de Texto, São Paulo,2010. 216p.

MELLO, C.R. et al. Erosividade mensal e anual da chuva no Estado de Minas Gerais. Pesquisa Agropecuária Brasileira. V 42. N4. Brasília, 537-545, 2007. Disponível em:< http://www.scielo.br/pdf/pab/v42n4/12>Acesso em: 20 de jan., 2014.

MELLO, C. R. et al. Krigagem e Inverso do Quadrado da Distância para interpolação dos parâmetros da equação de chuvas intensas. R. Bras. Ci. Solo. v. 27. N 5,Viçosa.p. 925-933, 2003. Disponível em:<http://www.scielo.br/scielo.php?script=sci_arttext\&pid=S0100-06832003000500017>Acesso em: 20 de jan., 2014.

NASCIMENTO, M. A. L do. Estudo dos processos erosivos na bacia do ribeirão João Leite em Goiânia. (Tese de doutorado). São Paulo: USP, 1998.

OLIVEIRA, F.A. Estudo do aporte sedimentar em suspensão na Baía da Babitonga sob a ótica da geomorfologia. 2006. Tese (Doutorado em Geografia Física) - Faculdade de Filosofia, Letras e Ciências Humanas, Universidade de São Paulo, São Paulo, 2007. Disponível em:

$<$ http://www.teses.usp.br/teses/disponiveis/8/8135/tde-27052007-143328/pt-br.php> Acesso em: 20 de jan. 2014.

OLIVEIRA, L. A; GONÇALVES, R. M; MARTINS, F.P. Contraste de Condutividade Hidráulica em Solos de Texturas Arenosa e Argilosa Encontrados nos Tributários da Margem Esquerda do Rio Tijuco, Município de Ituiutaba, Estado de Minas Gerais, Brasil. Caminhos de Geografia, Uberlândia v. 11, n. 33 mar 2010 p. 230 - 243. Disponível em:<http://www.seer.ufu.br/index.php/caminhosdegeografia/article/view/16139/9083> Acesso em 13 de set, 2013.

PEREIRA, J.S. Avaliação das Perdas de Solos por Erosão Laminar na Área de Influência da UHE Amador Aguiar I - MG. 2014, 170.f. (Dissertação de Mestrado) - Universidade Federal de Uberlândia, Uberlândia. Disponível em: < https://repositorio.ufu.br/handle/123456789/16206> Acesso em 13 de out, 2015.

RITTER, J..; ENG, P. Soil Erosion - Causes and Effects. Fact Sheet. Ontário v. 87.040. out. 2012. Disponível em:< http://www.omafra.gov.on.ca/english/engineer/facts/12-053.htm\#3> Acesso em: 17 de out., 2013.

RODRIGUES, M.T. et al. Utilização de métodos de interpolação para análise espacial pluviométrica na Bacia Hidrográfica do Paraíba do Meio - Alagoas e Pernambuco. [S.I.:s.n., entre 2011 e 2013]. Disponível em: <http://sic2011.com/sic/arq/21068475392722106847539.pdf> Acesso em: 14 de jan., 2013.

SILVA, A. M. da.; ALVARES, C. A.; WATANABE, C.H. Natural Potential for Erosion for Brazilian Territory. In: GODONE, D.; STANCHI, S. Soil Erosion Studies. Croácia, In:Tech Books, 2011. p. 3-24. Disponível em: <www.intechopen.com > Acesso em: 25 de jan., 2014.

SILVA, K. R. et al. Interpolação Espacial da Precipitação no Estado do Espírito Santo. Floresta e Ambiente. [S.I.], v.18, n. 4,p. 417- 427, out./dez 2011. Disponível em:<http://www.floram.org/files/v18n4/v18n4a8.pdf> Acesso em: 20 de jan., 2014.

TAO, T.et al. Uncertainty analysis of interpolation methods in rainfall spatial distribution-a case of small catchment in Lyon. Journal of Water Resource and Protection 2009; 2:136-144. Disponível em: http://www.oalib.com/paper/3100\#.UuFWFRBTvlU Acesso em 12 de jan. 2013.

WISCHMEIER, W.H.; SMITH, D.D. Predicting rainfall erosion losses: a guide to conservation planning. Washington: USDA/ARS.1978.58p. Disponível em: <http://naldc.nal.usda.gov/download/CAT79706928/PDF> Acesso em 11 de jun. 2012.

das Águas, A. N. (2009). Sistema de Informação Hidrológica - HIDROWEB, Disponível em: <http://hidroweb.ana.gov.br> Acesso em: 05 set. 2013, Brasil.

Recebido em: 04/11/2017

Aceito para publicação em: 28/06/2018 